\title{
High Variability of Iron Status in Adolescent during Pregnancy in Côte d' Ivoire
}

\author{
Mathieu Nahounou Bleyere ${ }^{1 *}$, Augustin Kouaho Amonkan², Mama Kone', Duni Sawadogo ${ }^{3}$ and Paul Angoué Yapo ${ }^{1}$ \\ ${ }^{1}$ Training and Research Unit of Natural Sciences, Nangui Abrogoua University, Côte d'Ivoire \\ ${ }^{2}$ Unit Training and Research of Biosciences, Félix Houphouët-Boigny University, Côte d'lvoire \\ ${ }^{3}$ Training and Research Unit of the Biological and Pharmaceutical Sciences, Felix Houphouet-Boigny University, Côte d'Ivoire
}

\begin{abstract}
Background: Iron metabolism in adolescents during pregnancy is degraded in the world. And yet, very few studies in Côte d'Ivoire are devoted to this public health concern.

Methods: This study aims to evaluate and characterize possible changes in iron metabolism in adolescents during pregnancy. Our study involved 112 adolescents aged 15 to 19 in consultation in urban community health centers of Abidjan (Côte d'Ivoire). In each adolescent, a blood sample was taken at bend of the elbow in morning on an empty stomach. These blood samples were collected in tubes with anticoagulant (EDTA) and dry tubes. The haematological and biochemical parameters were determined to assess iron status of adolescent in the three trimesters of pregnancy.

Results: Findings of study showed that iron stores and all evaluation parameters of iron metabolism were altered in adolescents during pregnancy. Haematological parameters except for $\mathrm{MCH}$ and $\mathrm{MCHC}$ and serum iron, saturation coefficient of transferrin and serum ferritin were decreased in the third trimester of pregnancy. Conversely, serum transferrin and total iron binding capacity were increased at this same trimester of pregnancy. Anaemia prevalence of $77.7 \%$ among study subjects was observed in third trimester of pregnancy. Moreover, at this stage of pregnancy, no adolescent has indicated normal biological parameter of iron metabolism. In this sense, observed components of iron status were, iron deficiency, iron deficiency anaemia, inflammatory anaemia and inflammatory anaemia associated with iron deficiency. Iron deficiency anaemia is most prevalent among adolescents with $76.8 \%$ in the third trimester of pregnancy.
\end{abstract}

Conclusion: Iron metabolism in adolescents of Abidjan is highly altered. This degradation is more significant in third trimester of pregnancy.

Keywords: Iron metabolism; Iron deficiency; Iron deficiency anaemia; Adolescent; Pregnancy; Côte d'Ivoire

\section{Introduction}

Double nutritional burden is nowadays a real public health concern in human nutrition [1-3]. Iron is a micronutrient whose coverage needs within human species is an essential component of a double nutritional burden $[4,5]$. Iron metabolism is severely degraded for several reasons among populations to lead to either iron deficiency or iron overload. Iron deficiency is the most common nutritional disorder in world [6]. It is the main cause of anaemia from several studies and would apply 4 to 5 billion subjects according to age. Strata of population most vulnerable are children, adolescents and women of childbearing age including pregnant women $[7,8]$. Iron is an essential micronutrient for many biological functions, including oxygen transport, electron transfer, and several enzymatic activities.

Iron is in the body with very small quantities. His contribution in body is mainly through diet [9-11]. In developing countries, bioavailability of iron and some factors (infectious and inflammatory syndromes) expose people to iron deficiency (60-80\%). Conversely, iron deficiency is lower in industrialized countries (10-20\%) [12,13]. Iron deficiency worsens with age and physiological state of pregnancy populations. Adolescents whose high iron needs and growth is still ongoing, represents a layer which is very vulnerable during pregnancy. Adolescence is characterized by rapid growth accompanied by profound changes in metabolic, hormonal and psychological exposed to nutritional deficiencies [14-16]. Iron deficiency has dramatic consequences on immunity, resistance to infection, physical ability to exercise and especially intellectual performance $[17,18]$. World Health
Organization (WHO) has developed programs to identify groups at risk and achieve iron supplementation enrichment of regular consumer products [19].

In Côte d'Ivoire, several studies on iron metabolism were devoted to women of reproductive age, infants and children [20,21]. In contrast, very little work, were conducted in adolescents for early detection of iron deficiency and types of anaemia [22]. And yet, adolescents constitute a layer of population highly vulnerable during pregnancy in developing countries. Therefore, this study aims to assess iron status in adolescents throughout the three trimesters of pregnancy in Côte d'Ivoire. Thus, our study reports possible changes of iron status biological indicators during pregnancy. In this context, our work plan also is to determine different components of iron status in adolescents during pregnancy. Furthermore, this study identifies which component of iron metabolism in adolescents is more frequent in pregnancy. In addition, this work reveals the physiological stage of pregnancy during which iron balance in adolescents would be altered.

${ }^{*}$ Corresponding author: Bleyere Mathieu Nahounou, Training and Research Unit of Natural Sciences, Nangui Abrogoua University; 02 BP 801 Abidjan 02 (Côte d'Ivoire), Tel: +225-45-439-944, +225-60-418-108; E-mail: bleyere@yahoo.fr

Received March 28, 2013; Accepted May 06, 2013; Published May 10, 2013

Citation: Bleyere MN, Amonkan AK, Kone M, Sawadogo D, Yapo PA (2013) High Variability of Iron Status in Adolescent during Pregnancy in Côte d'Ivoire. J Blood Disorders Transf 4:138. doi:10.4172/2155-9864.1000138

Copyright: (c) 2013 Bleyere MN, et al. This is an open-access article distributed under the terms of the Creative Commons Attribution License, which permits unrestricted use, distribution, and reproduction in any medium, provided the original author and source are credited. 


\section{Materials and Methods}

\section{Study population}

This was a longitudinal and descriptive study with analytical components. Subjects in this study aged 15 to 19 years, were recruited January 2010 to October 2010 in 4 urban community health centers, of Abidjan (Côte d'Ivoire). These are urban and health centers of Abobo south, south Cocody, urban community health centers "Les Hortensias" Port-Bouet and Municipal Hospital of Port-Bouet (Figure 1). A total of 112 pregnant adolescents in consultation in these four health centers were selected based on clinical data to exclude those with complications of hypertension, diabetes and rheumatism. This group of volunteer adolescents is followed from first trimester to third trimester of pregnancy. This study was approved by the Ministry of Higher Education and Scientific Research and the Ministry of Health and Population of the Republic of Côte d'Ivoire.

Study population had an average age of $17.6 \pm 0.1$ years. Mean number of these adolescents' pregnancy was $3 \pm 0.3$. Only the current pregnancy was taken into account in this study. The means of parity space between the last two pregnancies were respectively $0.6 \pm 0.1$ and $17.8 \pm 2$ months. The mean values of body mass index were respectively $21.5 \pm 0.4 \mathrm{~kg} \cdot \mathrm{m}^{-2}, 24.2 \pm 0.4 \mathrm{~kg} \cdot \mathrm{m}^{-2}$ and $26.1 \pm 0.4 \mathrm{~kg} \cdot \mathrm{m}^{-2}$ in first, second and third trimesters of pregnancy. The adolescent subjects have presented underweight during pregnancy in the proportions of $23.2 \%$, $26.8 \%$ and $15.2 \%$ respectively in the first, second and third trimesters of pregnancy (Table 1). This table 1 summarized also other characteristics of the study population. These characteristics concerned marital status, education, nutrition, observation and malaria anemia therapy. In addition, the diet of these adolescents is based on cereals in general and not dietary supplements.

\section{Samples and assays of biological parameters}

In each pregnant adolescent a blood sample was collected by venipuncture on a dry and EDTA tubes of $5 \mathrm{ml}$. Blood sampling was performed on fasting in elbow in morning and during each trimester of

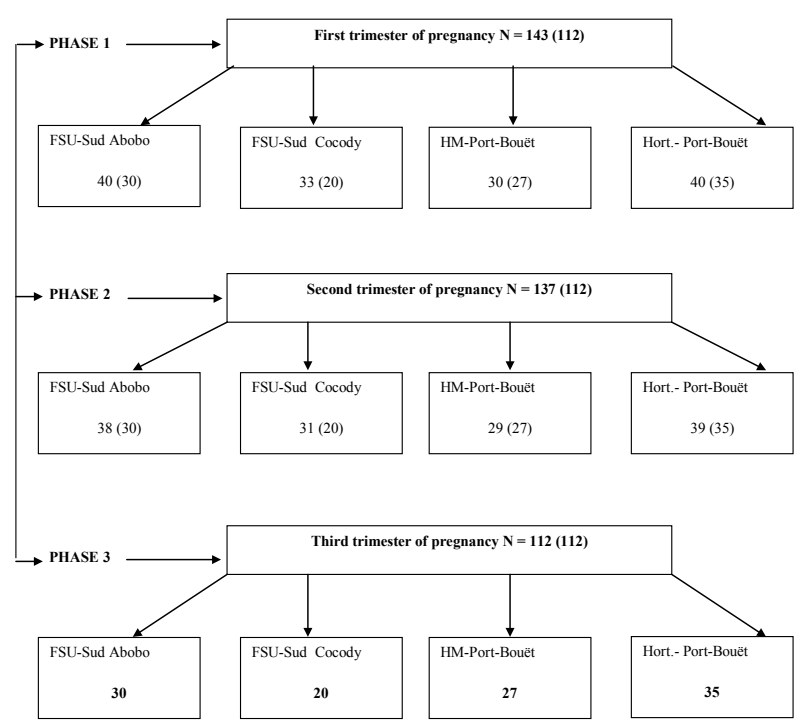

Figure 1: Different number of selected women according to the phases of study. $\mathrm{N}$ : Observed number for each phase of selected subjects; FSU: Communauty urban center; HM: municipal Hospital; Hort: "Hortensia"; Used number in study are in brackets pregnancy (between 8 and 15 weeks of pregnancy in the first trimester, between 16 and 28 weeks of pregnancy for the second trimester and between 28 and 36 weeks for the last trimester of pregnancy). Haematological parameters were immediately measured on samples collected in EDTA tubes by a haematological analyzer "Sysmex automatic Poch-100i” (1-5-1 Wakinohama-Kaigandori, Chuo-Ku, Kobe 651-0073, Japan). Samples collected in dry tubes were centrifuged at 3000 tours/ min during 5 minutes and the serum was used for the determination of biochemical parameters. Iron concentrations were determined by the colorimetric method from kit "Iron FerroZine". The rates of transferrin and ferritin were estimated by immunoturbidimetric method according respectively to kits "Transferrin Immunoturbidimetric" and "Ferritin Turbilatex." The reagents of such analyzes have been provided by Spinreact SA company (Ctra-Santa Coloma, Spain/www.spinreact. com). LisaBio 300 (Hycel group, Pouilly en Auxois, France) allowed the reading values serum iron, transferrin and ferritin. Each assay of blood sample from same sample was duplicated to minimize potential manipulation errors. The average of these obtained 2 values was used.

Total iron binding capacity (TIBC), saturation coefficients of transferrin (SCT) and iron stores have been obtained by calculations as follows:

TIBC $(\mu \mathrm{mol} / \mathrm{l})=25$. Serum transferrin $(\mathrm{g} / \mathrm{l})[23]$.

SCT $(\%)=100$. Serum iron $(\mu \mathrm{mol} / \mathrm{l})] /$ TIBC $(\mu \mathrm{mol} / \mathrm{l})[23]$.

For Iron stores: $1 \mu \mathrm{g} / \mathrm{l}$ of serum ferritin $=8 \mathrm{mg}$ of iron stores [24].

\section{Evaluation and statistical analysis of biological parameters}

The results of study are expressed as averages associated with standard errors of mean (SEM). The evaluation of iron status biological indicators were performed according to recommendations of WHO, French Society of Clinical Biology, French Society of Haematology (Group of Cellular Haematology), Society nutrition and dietetics French (France) and Center of disease control and prevention [6,23,25,26]

The analysis of variance (ANOVA) with repeated measures multivariate tests involving as post hoc Newman-Keuls test were used to compare the means of biological parameters between the different stages of pregnancy. These statistical analyzes were performed by computer program Statistica Statsoft Windows version 7.1 [27]. For comparisons of various obtained proportions, Log likelihood ratio test (Test "G") was conducted by statistical software " $R$ " Windows version 2.0.1 [28]. A value of $p<0.05$ was considered as indicative of significance.

\section{Results}

\section{Changes in haematological parameters during pregnancy}

The figure 2 was shown the changes in haematological parameters during pregnancy in adolescents. The results were revealed that red blood cells, hemoglobin, hematocrit and mean corpuscular volume (MCV) were decreased during the pregnancy. This decrease was more significant in the third trimester of pregnancy. However, mean corpuscular hemoglobin $(\mathrm{MCH})$ and mean corpuscular hemoglobin concentrations (MCHC) were not recorded the modifications during the three trimesters of pregnancy (Figure 2).

The findings of this work were reported the significant decrease of serum fer, saturation coefficient of transferrin (SCT) and serum ferritin throughout the pregnancy in adolescents. Yet, serum transferring and total iron binding capacity (TIBC) during the pregnancy of adolescents. Biochemical parameters changes during were more indicated in the third trimester (Figure 3). 

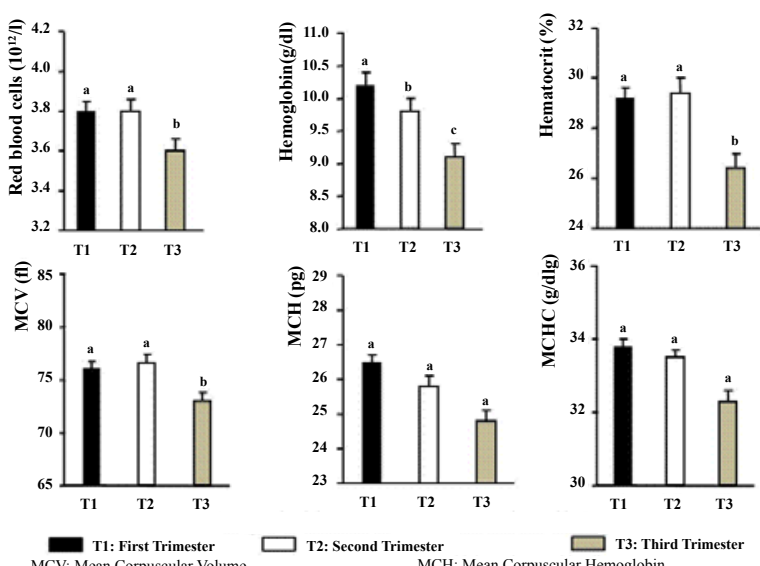
MCV: Mean Corpuscular Volume
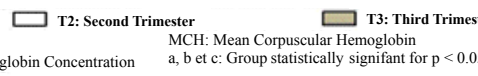

Figure 2: Changes in Haematological parameters during pregnancy.

\section{Evolution of iron stores and main biological parameters proportions during pregnancy}

Findings of study were revealed that iron stores were progressively decreased troughout the three trimesters of pregnancy. Furthermore, proportions of main haematological parameters were summarized in table 2. According to this table, the prevalences of anaemia during pregnancy were more significant. In the same way, $77.7 \%$ of adolescents were anaemic at the third trimester of pregnancy. In addition, the prévalences of severe anaemia were observed in adolescents throughout pregnancy $(23.2 \%, 15.2 \%$ and $8 \%$ respectively). Depending on variation of erythrocytes parameters, Hypochromic Microcytic Anaemia (HMA), Hypochromic Normocytic Anaemia (HNA), Normochromic Normocytic Anaemia (NNA) and Normochromic Microcytic Anaemia (NMA) were reported in adolescents during pregnancy. Among these types of anaemia, Hypochromic Microcytic Anaemia (HMA) was significantly more prevalent with $35.7 \%, 33.9 \%$ and $52.7 \%$ respectively at first, second and third trimesters of pregnancy in study population. Furthermore, the prévalences of microcytosis and hypochromia were more recorded at last trimester of pregnancy with $80.4 \%$ and $83.9 \%$ respectively. Nevertheless, no macrocytosis was observed among pregnant adolescents in our study (Table 2).

Several adolescents were presented values below normal values of serum iron, saturation coefficients of transferring and serum ferritin during pregnancy. In contrast, a high number of adolescents during pregnancy were shown values of serum transferrin and total iron binding capacity above references. This observation was more important at the third trimester of pregnancy in these study subjects (Table 3). It is also well to note that the iron stores of adolescents were strongly depleted in the third trimester of pregnancy.

\section{Variation of iron status components during pregnancy in adolescents}

The results of evaluation of all biological parameters of iron status were shown that very few adolescents had a normal iron status during pregnancy. In the same way, all adolescents (112) in our study reported abnormal iron status in the last trimester of pregnancy.

Abnormal iron status among these adolescents was included iron deficiency (ID), iron deficiency anaemia (IDA), inflammatory anaemia (IA) and inflammatory anaemia associated with iron deficiency (IA+ID).

\begin{tabular}{|c|c|c|c|}
\hline \multirow[t]{2}{*}{ Characteristics } & \multicolumn{3}{|c|}{ Stages of pregnancy (Trimesters) } \\
\hline & First & Second & Third \\
\hline & n (\%) & n (\%) & n (\%) \\
\hline Age (years) & \multicolumn{3}{|c|}{$17.6 \pm 0.1$} \\
\hline $15-17$ & \multicolumn{3}{|c|}{$48(42.9)$} \\
\hline $17-19$ & \multicolumn{3}{|c|}{$64(57.1)$} \\
\hline $\begin{array}{l}\text { Body mass index } \\
\left(\mathrm{kg} \cdot \mathrm{m}^{-2}\right)\end{array}$ & $21.5 \pm 0.4$ & $24.2 \pm 0.4$ & $26.1 \pm 0.4$ \\
\hline$<18.5$ & $26(23.2)$ & $30(26.8)$ & $17(15.2)$ \\
\hline $18.5-26$ & $72(64.3)$ & $60(53.6)$ & $87(77.7)$ \\
\hline$>26$ & $14(12.5)$ & $22(19.6)$ & $8(7.1)$ \\
\hline Gravidity & \multicolumn{3}{|c|}{$3 \pm 0.2$} \\
\hline Primigravidae & \multicolumn{3}{|c|}{$27(24.1)$} \\
\hline Multigravidae & \multicolumn{3}{|c|}{85 (75.9) } \\
\hline Parity & \multicolumn{3}{|c|}{$0.6 \pm 0.1$} \\
\hline Nulliparous & \multicolumn{3}{|c|}{$80(71.4)$} \\
\hline Primiparous & \multicolumn{3}{|c|}{$19(17)$} \\
\hline Multiparous & \multicolumn{3}{|c|}{$13(11.6)$} \\
\hline $\begin{array}{l}\text { Space between births } \\
\text { (Months) }\end{array}$ & \multicolumn{3}{|c|}{$17.8 \pm 2$} \\
\hline$<36$ & \multicolumn{3}{|c|}{$100(89.3)$} \\
\hline$>36$ & \multicolumn{3}{|c|}{$12(10.7)$} \\
\hline \multicolumn{4}{|l|}{ Matrimonial status } \\
\hline Married & \multicolumn{3}{|c|}{$2(1.8)$} \\
\hline Single & \multicolumn{3}{|c|}{$105(93.8)$} \\
\hline Concubinage & \multicolumn{3}{|c|}{$5(4.4)$} \\
\hline \multicolumn{4}{|l|}{ Education attainment } \\
\hline Uneducated & \multicolumn{3}{|c|}{$39(34.8)$} \\
\hline Primary school & \multicolumn{3}{|c|}{$19(17)$} \\
\hline Secondary school & \multicolumn{3}{|c|}{$54(48.2)$} \\
\hline $\begin{array}{l}\text { Number of meals per } \\
\text { day }\end{array}$ & $2.5 \pm 0.1$ & $2.8 \pm 0.1$ & $2.6 \pm 0.1$ \\
\hline$<3$ & $61(50)$ & $35(31.3)$ & $31(27.7)$ \\
\hline$>3$ & $61(50)$ & $68(60.7)$ & $79(70.5)$ \\
\hline \multicolumn{4}{|l|}{ Antianaemic } \\
\hline No & $14(12.5)$ & $9(8)$ & $1(0.9)$ \\
\hline Some times & $44(39.3)$ & $35(31.3)$ & $32(28.6)$ \\
\hline Yes & $54(48.2)$ & $68(60.7)$ & $79(70.5)$ \\
\hline \multicolumn{4}{|l|}{ Antimalarial } \\
\hline No & $6(5)$ & $0(0.0)$ & $0(0.0)$ \\
\hline Some times & $22(20)$ & $(0.9)$ & $(18.4)$ \\
\hline Yes & $84(75)$ & $111(99.1)$ & $91(81.6$ \\
\hline
\end{tabular}

$\mathrm{n}$ : Number of observed subjects in each group

Table 1: General characteristics of study population.

Among these components of iron status, iron deficiency anaemia (IDA) was significantly more prevalent with $76.8 \%$ at the third trimester of pregnancy in adolescents.

In addition, inflammatory anaemia (IA) and inflammatory anaemia associated with iron deficiency (IA+ID) were observed less during the teenage pregnancy of our study (Table 4).

\section{Discussion}

Our study shows that during pregnancy of adolescents, all evaluation biological parameters of iron metabolism are altered. This degradation relates haematological and biochemical indicators in last trimester of pregnancy. Changes in these parameters leads to highly elevated prevalence rate of anemia among adolescent during pregnancy. Anaemia is increased in third trimester of pregnancy with $77.7 \%$ of adolescents in our study. This prevalence is sufficiently above of those reported by some authors of Côte d'Ivoire in 225 women of reproductive age (42\%) and 411 non-pregnant women with $43.6 \%$ [21,22]. However, 
prevalence of anaemia in 531 pregnant women in this conntry is $81 \%$ durind the third trimester of pregnancy.

Work in United State of america (USA) was indicated that in 58 pregnant Caucasian adolescents, $22 \%$ were anaemic in third trimester of pregnancy [29]. In addition, some studies were recorded that, as pregnancy progressed, prevalence of anaemia increased in pregnant women of Côte d'Ivoire and African American pregnant adolescents $[20,30,31]$. Thus, in a retrospective medical chart review of 918 adolescents, some authors were reported prevalence of anaemia to be $10 \%$ of pregnant adolescents in first trimester, 20\% in second trimester and $57 \%$ in third trimester [30]. Similar findings were reported with the prevalence of anaemia rising from $31 \%$ in the second trimester to $63 \%$ in the third trimester in 80 adolescents [31].

In contrast, our study shows that prevalence of anaemia declined in second trimester before rising in third trimester of pregnancy $(67.9 \%$, $53.6 \%$ and $77.7 \%$ respectively).

This observation could be explained by observance to anaemia and malaria therapies in study population.

Anaemia is known as finality of a dynamic process. Anaemia in its first phase begins at the depletion of various reserves which contribute to the synthesis of red blood cells. Upstream reserves of folate, B vitamins and mostly iron are collapsed [32]. This study reveals that in pregnant adolescents, iron stores and serum ferritin easily mobilized, were decreased gradually during the three trimesters of pregnancy (59.8\%, $64.3 \%$ and $88.6 \%$ respectively). This result is similar to previous study in pregnant women from Abidjan (Côte d'Ivoire) with 57\%, $65 \%$ and respectively according to trimesters to those in 92 pregnant adolescents of New York (USA) with $65 \%$ of iron depletion in second trimester of pregnancy $[20,33]$.

Reduction of iron stores has direct consequence of decrease in circulating iron and increase in protein transport within body. Indeed, lower concentrations of serum ferritin immediately induces the collapse of serum iron, saturation coefficients of transferrin and increased serum transferrin and total iron binding capacity. This finding has been reported in our investigation. And it summarizes the second phase of the dynamic mechanism of anaemia. The same observation was indicated respectively in the United States of America and South Africa among adolescents during pregnancy $[31,34,35]$.

The consequences of the second phase of anaemia development caused by decreased ferritin, lead downstream to Changes in
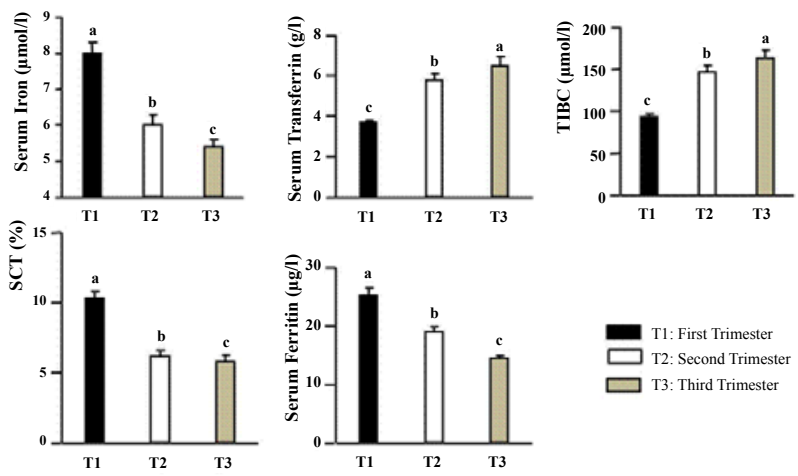

TIBC: Total Iron Binding capacity

SCT: Saturation coefficient of Transferrin

bete: Goup statistically signifat for $\mathrm{p}<0.05$

Figure 3 : Evolution of Biochemical parameters during pregnancy

\begin{tabular}{|c|c|c|c|c|}
\hline \multirow{2}{*}{$\begin{array}{l}\text { Haematological } \\
\text { parameters }\end{array}$} & Stages of pregnancy (Trimesters) & \multirow{2}{*}{ p values } \\
\cline { 2 - 3 } & First & Second & Third & \multirow{2}{*}{} \\
\cline { 2 - 3 } & $\mathrm{n}(\%)$ & $\mathrm{n}(\%)$ & $\mathrm{n}(\%)$ & \\
\hline Hemoglobin (g/dI) & & & & \\
\hline $6-10.5 / 11$ & $76(67.9)$ & $60(53.6)$ & $87(77.7)$ & $0.001(\mathrm{~S})$ \\
\hline $10.5 / 11-13.9$ & $36(32.1)$ & $52(46.4)$ & $25(22.3)$ & $0.005(\mathrm{~S})$ \\
\hline Types of anaemia & & & & \\
\hline Crude & $10(8.9)$ & $33(29.5)$ & $64(57.1)$ & $9.910^{-10}(\mathrm{~S})$ \\
\hline Moderate & $40(35.7)$ & $10(8.9)$ & $24(21.4)$ & $9.110^{-5}(\mathrm{~S})$ \\
\hline Severe & $26(23.2)$ & $17(15.2)$ & $9(8)$ & $0.01(\mathrm{~S})$ \\
\hline HMA & $40(35.7)$ & $38(33.9)$ & $59(52.7)$ & $0.02(\mathrm{~S})$ \\
\hline HNA & $9(8)$ & $7(6.3)$ & $4(3.6)$ & $0.4(\mathrm{NS})$ \\
\hline NNA & $21(18.8)$ & $12(10.7)$ & $21(18.8)$ & $0.1(\mathrm{NS})$ \\
\hline NMA & $6(5.4)$ & $3(2.7)$ & $3(2.7)$ & $0.5(\mathrm{NS})$ \\
\hline Hematocrit (\%) & & & & \\
\hline $11.5-32 / 33$ & $88(78.6)$ & $65(58)$ & $87(77.7)$ & $0.02(\mathrm{~S})$ \\
\hline $32 / 33-42.1$ & $24(21.4)$ & $47(42)$ & $25(22.3)$ & $0.005(\mathrm{~S})$ \\
\hline & & & & \\
\hline $51.5-80$ & $85(75.9)$ & $76(67.9)$ & $90(80.4)$ & $0.06(\mathrm{NS})$ \\
\hline $80-98.7$ & $30(24.1)$ & $36(32.1)$ & $22(19.6)$ & $0.09(\mathrm{NS})$ \\
\hline MCH (pg) & & & & \\
\hline $15.9-27 / 31-34.1$ & $69(61.6)$ & $74(66.1)$ & $94(83.9)$ & $0.02(\mathrm{~S})$ \\
\hline $27-31$ & $43(38.4)$ & $38(33.9)$ & $18(16.1)$ & $0.002(\mathrm{~S})$ \\
\hline
\end{tabular}

$\mathrm{n}$ : Number of observed subjects in each group;

a: Haemotological reference parameters according to French Society of haematology [21,52];

b: for these two haematological parameters, the reference values were defined according to the stage of pregnancy to obtain prevalences of types' anaemia and hemodilution; hemoglobin levels are similar in the first and third trimesters of pregnancy, it is the same for hematocrit. MCV: Mean corpuscular volume; $\mathrm{MCH}$ Mean corpuscular hemoglobin; HMA: Hypochromic Microcytic Anaemia; HNA Hypochromic Normocytic Anaemia; NNA: Normochromic Normocytic Anaemia; NMA: Normochromic Microcytic Anaemia; S: Difference statistically significant for $p$ $<0.05$; NS: Difference not statistically significant for $p>0.05$

Table 2: Proportions of main haematological parameters during pregnancy.

haematological parameters. This is the third and final phase of the evolutionary process of anaemia. Erythrocyte indices vary, resulting in microcytosis, macrocytosis and hypochromia in body of population. In the same sense, adolescents in our study reported a high prevalence of microcytosis $(75.9 \%, 67.9 \%$ and $80.4 \%$ respectively) and hypochromia $(61.6 \%, 66.1 \%$ and $83.9 \%$ respectively) in the three trimesters of pregnancy. These high rates of microcytosis and hypochromia led to decreases in hemoglobin of study subjects. This is anaemia, final phase of iron stores degradation. This iron stores alteration is due to several reasons. The main reason for the collapse of iron stores is of nutritional origin. Adolescents during pregnancy have altered nutritional status. This alteration of nutritional status is increased in third trimester of pregnancy $[36,37]$. This could justify the iron stores degradation of study subjects.

Moreover, physiologic iron requirements are three times higher in pregnancy than they are in menstruating women [38]. Approximately $1200 \mathrm{mg}$ must be acquired from the body iron store or from the diet by the end of pregnancy to meet both the requirements of the mother for the expansion of her circulating red cell mass and the demands of the developing fetus [39]. The average requirement for a menstruating woman for the same period of time is 400 [38]. The increased requirement is therefore $800 \mathrm{mg}$. This additional demand can be provided by diet and antianaemic drugs. However, studies have shown that adolescents begin pregnancy with depleted iron stores [22,39-42]. And yet, the demand for additional iron is not spread evenly throughout pregnancy. In the first trimester, requirements are actually reduced because menstruation has ceased, the demands of the 
Citation: Bleyere MN, Amonkan AK, Kone M, Sawadogo D, Yapo PA (2013) High Variability of Iron Status in Adolescent during Pregnancy in Côte d'Ivoire. J Blood Disorders Transf 4:138. doi:10.4172/2155-9864.1000138

\begin{tabular}{|l|c|c|c|c|}
\hline \multirow{2}{*}{ Biochemical indicators } & \multicolumn{2}{|c|}{ Stages of pregnancy (Trimesters) } & \multirow{2}{*}{ p values } \\
\cline { 2 - 3 } & First & Second & Third & \\
\hline Iron stores $(\mathrm{mg})$ & $201.6 \pm 12$ & $152.8 \pm 6.4$ & $116 \pm 4$ & $0.02(\mathrm{~S})$ \\
\hline Serum iron $(\boldsymbol{\mu m o l} / \mathbf{l})$ & $\mathrm{n}(\%)$ & $\mathrm{n}(\%)$ & $\mathrm{n}(\%)$ & \\
\hline $1.6-7.16$ & $57(50.9)$ & $112(100)$ & $79(70.5)$ & $0.0004(\mathrm{~S})$ \\
\hline $7.16-19.9$ & $55(49.1)$ & $0(0)$ & $33(29.5)$ & $5.5 .10^{-16}(\mathrm{~S})$ \\
\hline Serum transferrin (g/l) & & & & \\
\hline $1.2-2$ & $14(12.5)$ & $9(8)$ & $2(1.8)$ & $0.009(\mathrm{~S})$ \\
\hline $2-3.6$ & $44(39.3)$ & $35(31.3)$ & $31(27.7)$ & $0.1(\mathrm{NS})$ \\
\hline $3.6-14.3$ & $54(48.2)$ & $68(60.7)$ & $79(70.5)$ & $0.02(\mathrm{~S})$ \\
\hline TIBC $(\boldsymbol{\mu m o l} / \mathbf{l})$ & & & & \\
\hline $30.5-50$ & $14(12.5)$ & $9(8)$ & $1(0.9)$ & $0.002(\mathrm{~S})$ \\
\hline $50-90$ & $44(39.3)$ & $35(31.3)$ & $32(28.6)$ & $0.1(\mathrm{NS})$ \\
\hline $90-356.3$ & $54(48.2)$ & $68(60.7)$ & $79(70.5)$ & $0.02(\mathrm{~S})$ \\
\hline SCT (\%) & & & & \\
\hline $0.5-15$ & $84(75)$ & $111(99.1)$ & $91(81.6)$ & $0.01(\mathrm{~S})$ \\
\hline $15-35$ & $28(25)$ & $1(0.9)$ & $21(18.7)$ & $2.5 .10^{-7}(\mathrm{~S})$ \\
\hline Serum ferritin $(\boldsymbol{\mu g} / \mathrm{l})$ & & & & \\
\hline $6.2-20$ & $67(59.8)$ & $72(64.3)$ & $97(88.6)$ & $0.004(\mathrm{~S})$ \\
\hline $20-96.1$ & $45(40.2)$ & $40(35.7)$ & $15(13.4)$ & $0.0002(\mathrm{~S})$ \\
\hline
\end{tabular}

$\mathrm{n}$ : Number of observed subjects in each group; TIBC: Total iron binding capacity; SCT: Saturation coefficient of transferring; S: Difference statistically significant for $p<0.05$; NS: Difference not statistically significant for $p>0.05$; the proportions of various biochemical parameters were defined according to established references $[21,23,24,53]$

Table 3: Iron stores and proportions of main biochemical indicators during pregnancy.

\begin{tabular}{|c|c|c|c|c|}
\hline \multirow{3}{*}{$\begin{array}{l}\text { Components of } \\
\text { iron status }\end{array}$} & \multicolumn{3}{|c|}{ Stages of pregnancy (Trimesters) } & \multirow[t]{3}{*}{$p$ values } \\
\hline & First & Second & Third & \\
\hline & $\mathrm{n}(\%)$ & $\mathrm{n}(\%)$ & $\mathrm{n}(\%)$ & \\
\hline Normal iron status & $13(11.6)$ & $11(9.8)$ & $0(0.0)$ & $0.0001(\mathrm{~S})$ \\
\hline Abnormal iron status & $99(88.4)$ & $101(90.2)$ & $112(100)$ & $0.04(\mathrm{~S})$ \\
\hline Iron deficiency & $27(24.1)$ & $40(35.7)$ & $25(22.3)$ & 0.06 (NS) \\
\hline $\begin{array}{l}\text { Iron deficiency } \\
\text { anaemia }\end{array}$ & $65(58)$ & $61(54.5)$ & $86(76.8)$ & $0.02(\mathrm{~S})$ \\
\hline $\begin{array}{l}\text { Inflammatory } \\
\text { anaemia }\end{array}$ & $6(5)$ & $0(0.0)$ & $1(0.9)$ & 0.02 (S) \\
\hline $\begin{array}{l}\text { Inflammatory } \\
\text { anaemia + Iron } \\
\text { deficiency }\end{array}$ & $1(1.3)$ & $0(0.0)$ & $0(0.0$ & 0.2 (NS) \\
\hline
\end{tabular}

$\mathrm{n}$ : Number of observed subjects in each group; The prevalences of the various components of iron status were defined depending on established references $[6,21,23,25,26,53], \mathrm{S}$ : Difference statistically significant for $p<0.05$; NS: Difference not statistically significant for $p>0.05$.

Table 4: Components of iron status during pregnancy

fetus are still small and the expansion of the maternal red cell mass has not yet started to occur. The need for additional iron commences early in the second trimester and reaches a peak toward the end of the third trimester, when requirements rise to between 4 and $6 \mathrm{mg} / \mathrm{d}$ [43]. In addition, adolescents know worst gynecological and obstetrical antecedents and large delays in consultations [44,45]. Furthermore, inflammatory and infectious syndromes are frequently observed among adolescents in developing countries [46-52]. All these events concurred to explain the high variability of iron metabolism in adolescents during pregnancy.

\section{Conclusion}

The study among pregnant adolescents of Abidjan reveals that all biological parameters of iron metabolism are altered during pregnancy. This alteration leads to high prevalence of anaemia during the three trimesters of pregnancy. Along the same lines, all adolescents in third

of pregnancy don't show normal values of biological parameter of iron metabolism assessment. Thus, iron deficiency, iron deficiency anaemia, inflammatory anaemia and inflammatory anaemia associated with iron deficiency are different components of iron status in adolescent pregnancy of Abidjan. In addition, iron deficiency anaemia is the most important among these components of iron metabolism.

Ultimately, pregnancy is a factor that degrades iron metabolism of pregnant adolescent in Abidjan, and this, in third trimester of pregnancy.

\section{Acknowledgements}

Authors are grateful to all laboratory managers and staff of urban community health centers of Abidjan/Côte d'Ivoire for their support during our investigations. Special thanks are also addressed to Dr. Leonie Clemence Kouonon for her guidance during drafting of this study. This research did not receive any specific grant from any funding agency in the public, commercial, or not-for-profit sector.

\section{References}

1. Kennedy G, Nantel G, Shetty P (2003) The scourge of hidden hunger: global dimensions of micronutrient deficiencies. Food Nutr Agric 32: 8-16.

2. FAO (2005) Assessment of the double burden of malnutrition in six case study countries. Rome, FAO.

3. Delisle HF (2008) Poverty: the double burden of malnutrition in mothers and the intergenerational impact. Ann N Y Acad Sci 1136: 172-184.

4. Ruel MT (2001) Can food-based strategies help reduce vitamin A and iron deficiencies? A review of recent evidence. Food Policy Review 5. Washington DC; IFPRI.

5. Shetty P (2002) Food and nutrition: the global challenge. In: Gibney MJ, Vorster $\mathrm{EHH}$, Kok FJ (eds.) Introduction to human nutrition. Blackwell Publishing, The Nutrition Society.

6. UNICEF/UNU/WHO (2001) Iron deficiency anemia: assessment, prevention and control. WHO/NHD/01.3 Geneva, Switzerland: WHO

7. Rossander-Hulthén L, Hallberg L (1996) Prevalence of iron deficiency in adolescents. In: Hallberg L, Asp N-G, eds. Iron nutrition in health and disease. p.149-156. London, John Libby\& Co.

8. WHO/FAO (2004) Vitamin and mineral requirements in human nutrition. 2nd édition. Geneva, WHO

9. Bothwell TH (1979) Iron metabolism in man. London, Blackwell Scientific Publications.

10. Mascotti DP, Rup D, Thach RE (1995) Regulation of iron metabolism: translational effects mediated by iron, heme, and cytokines. Annu Rev Nutr 15: $239-261$.

11. Kühn LC (1996) Control of cellular iron transport and storage at the molecular level. In: Hallberg LA, et al., eds. Iron nutrition in health and disease. p. 17-29. London, John Libbey \& Company.

12. $\mathrm{FAO} / \mathrm{WHO}$ (1988) Requirements of vitamin $\mathrm{A}$, iron, folate and vitamin $\mathrm{B} 12$ Report of a Joint FAO/WHO Expert Consultation. Rome: FAO. (FAO Food and Nutrition Series No. 23).

13. Berger J (2005) Anémie par carence en fer Avec des images et des données IFMT-M IRD, Hanoi, 30p.

14. [No authors listed] (1998) Recommendations to prevent and control iron deficiency in the United States. Centers for Disease Control and Prevention. MMWR Recomm Rep 47: 1-29.

15. WHO (2003) Youth and health: a challenge for society: Report of a WHO study on youth and health for all by the year 2000. Technical Report Series, No. 731 Geneva: World Health Organization, 1986

16. Leenstra T, Kariuki SK, Kurtis JD, Oloo AJ, Kager PA, et al. (2004) Prevalence and severity of anemia and iron deficiency: cross-sectional studies in adolescent schoolgirls in western Kenya. Eur J Clin Nutr 58: 681-691.

17. Hallberg L (1982) Iron absorption and iron deficiency. Hum Nutr Clin Nutr 36 259-278. 
Citation: Bleyere MN, Amonkan AK, Kone M, Sawadogo D, Yapo PA (2013) High Variability of Iron Status in Adolescent during Pregnancy in Côte d'Ivoire. J Blood Disorders Transf 4:138. doi:10.4172/2155-9864.1000138

18. Dallman PR (1986) Biochemical basis for the manifestations of iron deficiency. Annu Rev Nutr 6: 13-40.

19. UNICEF/UNU/WHO (2005) Déclaration conjointe de l'Organisation Mondiale de la Santé et du Fonds de Nations Unies pour l'Enfance: Focaliser sur l'anémie; vers une approche intégrée pour un contrôle efficace de l'anémie. http://www.who.org/publications/index.html (accessed April 5th 2005).

20. Nahounou Bléyéré M, Joulia Ekaza D, Yapo Angoué P, Datté Yao J, N'guessan Banga B, et al. (2007) [Heterogeneity of the iron status in the woman population during the pregnancy in Côte-d'Ivoire]. Ann Biol Clin (Paris) 65: 525-532.

21. Yapo PA, Bleyere MN, Joulia-Ekaza D, Yao JD, N'guessan BB et al. (2008) Prevalence of iron deficiency and anemia among women of childbearing age, pregnant and non-pregnant women. Ann Biol Clin Quebec 45 : 24-28.

22. Atto V, MN Bleyere, AB Konan, JY Datte, PA Yapo (2013). Depletion of Iron Stores and Main Associated Parameters in Adolescents of Côte d'Ivoire. Pak J Nutr $12: 188-196$.

23. Vernet M, Corberand J, David V, Deugnier Y, Frey J, et al. (2001) [Recommended algorithms of prescription in the diagnosis of iron deficiency and overload]. Ann Biol Clin (Paris) 59: 149-155.

24. Beard JL (2000) Iron requirements in adolescent females. J Nutr 130: 440 S-442S.

25. Institute of Medecine (IOM/USA) (1990) Comittte on nutritional status during pregnancy and lactation. Nutrition during pregnancy: weight gain and nutrient supplements. Washington DC. National Academy Press.

26. Société de Nutrition et de Diététique de Langue Française (2001) Anémies nutritionnelles (SNDLF). Cah Nutr Diét 36 (Hors série): 76-81. [In french].

27. Statsoft (2005) Statistica (Data Analysis Software System). Version 7.1 available at www. Statsoft.com. Accessed September 21st 2004.

28. Ihaka R, Gentleman R (1996) R: a language for data analysis and graphics. J computation graph statist 5: 299-314.

29. Gadowsky SL, Gale K, Wolfe SA, Jory J, Gibson R, et al. (1995) Biochemical folate, B12, and iron status of a group of pregnant adolescents accessed through the public health system in southern Ontario. J Adolesc Health 16 465-474.

30. Chang SC, O'Brien KO, Nathanson MS, Mancini J, Witter FR (2003) Hemoglobin concentrations influence birth outcomes in pregnant AfricanAmerican adolescents. J Nutr 133: 2348-2355.

31. Iannotti LL, O'Brien KO, Chang SC, Mancini J, Schulman-Nathanson M, et al. (2005) Iron deficiency anemia and depleted body iron reserves are prevalent among pregnant African-American adolescents. J Nutr 135: 2572-2577.

32. García-Casal MN, Osorio C, Landaeta M, Leets I, Matus P, et al. (2005) High prevalence of folic acid and vitamin B12 deficiencies in infants, children, adolescents and pregnant women in Venezuela. Eur J Clin Nutr 59: 1064-1070.

33. Young MF, Pressman E, Foehr ML, McNanley T, Cooper E, et al. (2010) Impact of maternal and neonatal iron status on placental transferrin receptor expression in pregnant adolescents. Placenta 31: 1010-1014.

34. Bailey LB, Mahan CS, Dimperio D (1980) Folacin and iron status in low-income pregnant adolescents and mature women. Am J Clin Nutr 33: 1997-2001.

35. Bopape MM, Mbhenyane XG, Alberts M (2008) The prevalence of anaemia and selected micronutrient status in pregnant teenagers of Polokwane Municipality in the Limpopo Province. S Afr J Clin Nutr 21: 332-336.

36. Moran VH (2007) Nutritional status in pregnant adolescents: a systematic review of biochemical markers. Matern Child Nutr 3: 74-93.

37. Moran VH (2007) A systematic review of dietary assessments of pregnan adolescents in industrialised countries. $\mathrm{Br} \mathrm{J}$ Nutr $97:$ 411-425.

38. Lynch SR (2000) The potential impact of iron supplementation during adolescence on iron status in pregnancy. J Nutr 130: 448S-451S.
39. Delisle $\mathrm{H}$ (1998) Food security, its links with nutrition and health. In: Delisle $\mathrm{H}$ Shaw DJ (Eds). The Quest for Food Security in the Twenty First Century. Can J Development Studies 19 (Special Issue): 307-21.

40. Creed-Kanashiro HM, Uribe TG, Bartolini RM, Fukumoto MN, Lopez TT, et al. (2000) Improving Dietary Intake to Prevent Anemia in Adolescent Girls through: Improving Adolescent Iron Status before Childbearing Community Kitchens in a Periurban Population of Lima, Peru. J Nutr 130: 459S-461S.

41. Delisle H, Chandra-Mouli V, deBenoist B (2000) "Should Adolescents Be Specifically Targeted for Nutrition in Developing Countries: To Address Which Problems, and How?" World Health Organization/International Nutrition Foundation for Developing Countries. Kurz KM, Galloway R (2000) Improving adolescent iron status before childbearing. J Nutr 130: 437S-439S.

42. Hallberg L, Hulten L (1996) Iron requirements, iron balance and iron deficiency in menstruating pregnant women. In: Iron Nutrition in Health and Disease (Hallberg, L. \& Asp, N.-G., eds.), pp.165-182. John Libbey \& Company.

43. Reime B, Schücking BA, Wenzlaff $P$ (2008) Reproductive outcomes in adolescents who had a previous birth or an induced abortion compared to adolescents' first pregnancies. BMC Pregnancy Childbirth 8: 4.

44. Gross K, Alba S, Glass TR, Schellenberg JA, Obrist B (2012) Timing of antenata care for adolescent and adult pregnant women in south-eastern Tanzania. BMC Pregnancy Childbirth 12: 16.

45. Nurdia DS, Sumarni S, Suyoko, Hakim M, Winkvist A (2001) Impact of intestinal helminth infection on anemia and iron status during pregnancy: a community based study in Indonesia. Southeast Asian J Trop Med Public Health 32: 14-22.

46. Weyermann M, Rothenbacher D, Gayer L, Bode G, Adler G, et al. (2005) Role of Helicobacter pylori infection in iron deficiency during pregnancy. Am J Obstet Gynecol 192: 548-553

47. Alaofe H, O'brien HT, Zee J (2006) The relationship between intestinal parasitic infections, absorbable iron intakes and anemia among adolescent girls from Benin. Méd Nut 42(1): 14-28.

48. Fuseini G, Edoh D, Kalifa BG, Hamid AW, Knight D (2010) Parasitic infections and anaemia during pregnancy in the Kassena-Nankana district of Northern Ghana. J Public Health Epidemiol 2: 48-52.

49. Senga EL, Harper G, Koshy G, Kazembe PN, Brabin BJ (2011) Reduced risk for placental malaria in iron deficient women. Malar J 10: 47.

50. Pullan RL, Gitonga C, Mwandawiro C, Snow RW, Brooker SJ (2013) Estimating the relative contribution of parasitic infections and nutrition for anaemia among school-aged children in Kenya: a subnational geostatistical analysis. BMJ Open 3.

51. FSH (French Society of Haematology-Pedagogical committee) (2006 [Hémogramme : indications et interpretation-Evaluation ] Haemogram Indication and interpretation-Evaluation, 121-145. [In french].

52. Rymer JC (1996) Aspects récents du métabolisme du fer ; les outils biochimiques de son exploration. Hematologie. 2 (1): 45-56. [Recent aspects of iron metabolism, biochemical tools of his exploration] [In french].
Citation: Bleyere MN, Amonkan AK, Kone M, Sawadogo D, Yapo PA (2013) High Variability of Iron Status in Adolescent during Pregnancy in Côte d'Ivoire. J Blood Disorders Transf 4:138. doi:10.4172/2155-9864.1000138 